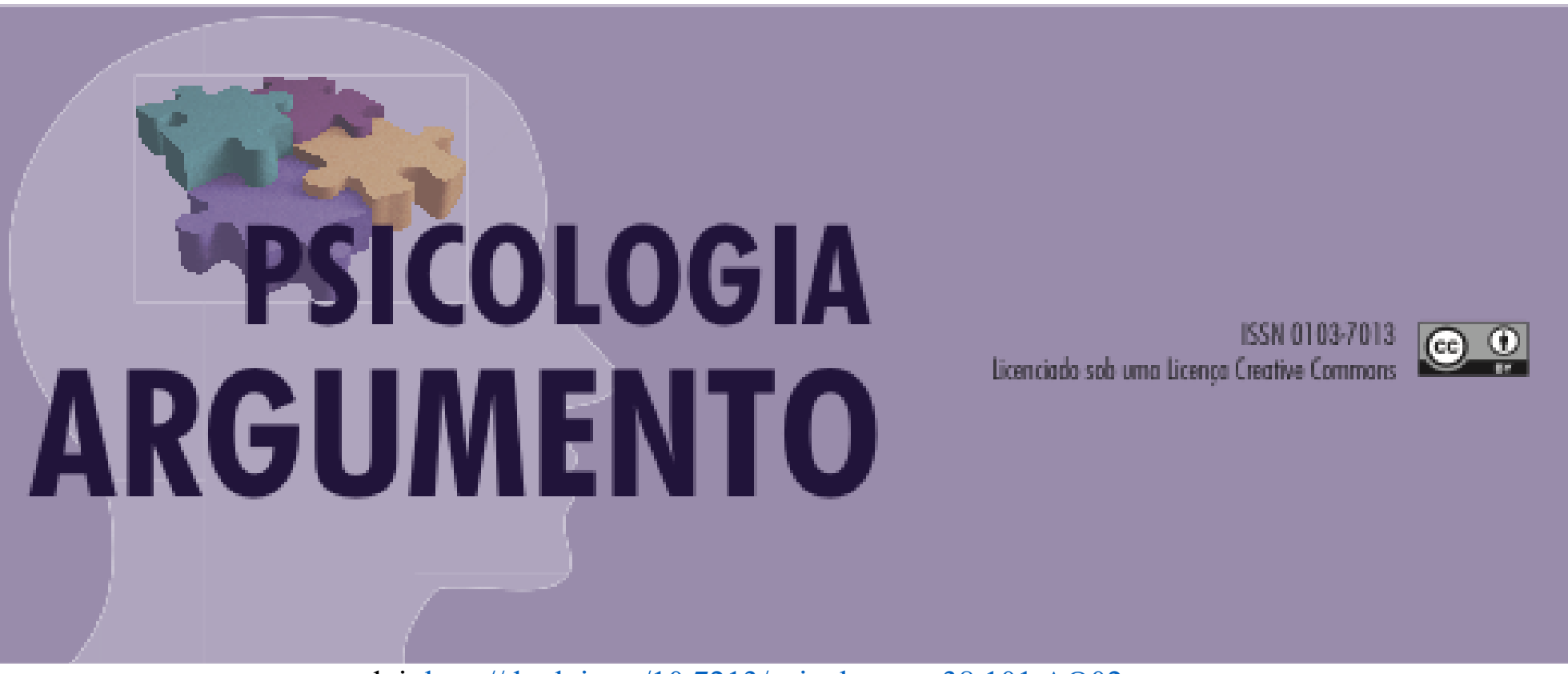

doi: http://dx.doi.org/10.7213/psicolargum.38.101.AO02

\title{
Psicólogos nas Políticas Públicas de Assistência Social: atuação em CRAS e interface com a formação acadêmica
}

\section{Psychologists in Public Policies of Social Work: performance at CRAS (Social Work Reference Centers) and interface with academic education}

\section{Psicólogos y Políticas Públicas de Asistencia Social: actuación en los Centros de Referencia en Asistencia Social (CRAS) e interfaz con la formación académica}

\author{
Dione Maria Menz \\ Mestra em Psicologia Universidade Tuiuti do Paraná, Doutoranda em Educação \\ Universidade Federal do Paraná, dionemenz@gmail.com \\ https://orcid.org/0000-0003-4349-5632 \\ Denise de Camargo \\ Professora e Pesquisadora da Universidade Tuiuti do Paraná e da Universidade Federal \\ do Paraná, denicamargo@gmail.com \\ https://orcid.org/0000-0001-9092-9988
}

\begin{abstract}
Resumo
Este artigo faz uma reflexão sobre práticas dos psicólogos atuantes nos Centros de Referência em Assistência Social (CRAS), na interface com a formação acadêmica. Objetiva contribuir para formação de psicólogos junto à Política Nacional de Assistência Social e à aplicação de políticas públicas que operacionalizam direitos e fortalecem garantias sociais. A produção dos dados ocorreu mediante entrevista com oito psicólogos de CRAS. A análise qualitativa de conteúdo gerou quatro categorias a posteriori, em torno dos temas seguintes: mal-estar de trabalhar no campo da assistência social; conflitos de identidade profissional; bom senso, ecletismo e conhecimentos da clínica tradicional como referências teóricas para o trabalho em CRAS; práticas
\end{abstract}


nos CRAS: fazeres dos psicólogos $\mathrm{x}$ conhecimentos necessários. A pesquisa indica a necessidade de rever a formação, compreendendo-se a Assistência Social enquanto Política Pública que afirma direitos, para a construção de práticas psicológicas que superem o modelo clínico individualizante essencialista, tradicionalmente aplicado à formação de psicólogos.

Palavras-chave: Políticas Públicas. Psicologia social. Serviço Social

\begin{abstract}
This article is a reflection on the interface between psychologists' practices at the Social Work Reference Centers (CRAS) and their academic education. It aims to contribute to psychologists' education, in view of the National Policy of Social Work, as well as the application of public policies that operationalize rights and strengthen social safeguards. Data collection was conducted by means of an interview with eight psychologists from CRAS. After the qualitative content analysis, four categories evolved on the following themes: Dissatisfaction with working in the field of the Social Work; Professional identity conflicts; Common sense, eclecticism and knowledge of the traditional clinic as the theoretical background for working at CRAS; CRAS practices: psychologists' work X required knowledge. The study points to the need of reviewing education, understanding Public Policy as reassuring rights, and constructing psychological practices that overcome the essentialist, individualist clinical model, traditionally applied to the psychologists' education.
\end{abstract}

Keywords: Public Policies. Social Psychology. Social Work.

\title{
Resumen
}

El presente artículo propone una reflexión acerca de las prácticas de psicólogos que actúan en los Centros de Referencia en Asistencia Social (CRAS), volcados en la interfaz con la capacitación académica. Se busca hacer una contribución para la formación de psicólogos que estén relacionados con la Política Nacional de Asistencia Social y también con la aplicación de politicas públicas que preserven los derechos y establezcan garantías sociales. La toma de los datos ocurrió mediante una encuesta con ocho psicólogos de dichos centros. El análisis cualitativo de contenido generó cuatro categorías a posteriori, volcadas en los siguientes temas: desazón por cuenta del trabajo en el ámbito de la asistencia social; enfrentamientos de identidad profesional; sensatez, eclecticismo y conocimientos de la atención médica tradicional como referencias teóricas para el trabajo en los CRAS; prácticas en los CRAS: quehaceres de los psicólogos contraponiéndose a los conocimientos obligatorios. La investigación sugiere la necesidad de que sea reevaluada la formación de los involucrados, comprendiendo la Asistencia Social como una acción de política pública responsable de la concretización de los derechos, garantizando la construcción de prácticas psicológicas que logren superar el modelo de atención médica de carácter individualizador esencialista, tradicionalmente utilizado en la formación de psicólogos.

Palabras clave: Políticas Públicas. Psicología Social. Servicio Social.

\section{Introdução}

As discussões que envolvem o papel e a prática da psicologia nas políticas públicas assumem contornos marcantes a partir de 1988, com a promulgação da Constituição Federal (CF), carinhosamente denominada Constituição Cidadã, que em seus diferentes capítulos faz a defesa dos direitos humanos fundamentais e das garantias sociais. 
Dentre seus avanços destaca-se o capítulo da seguridade social, composto pelo tripé saúde, previdência e assistência social. Esse último campo, a assistência social, a partir de 2005 operacionaliza o Sistema Único da Assistência Social (SUAS), estruturando assim seus respectivos equipamentos sociais: Centros de Referência em Assistência Social (CRAS) e Centros de Referência Especializada em Assistência Social (CREAS), convocando a psicologia para um trabalho multiprofissional, de base territorial, interdisciplinar e intersetorial, o que implica na revisão de suas práticas e saberes. Vale destacar que esse é um campo em permanente disputa e construção; prova disso é que, embora a Lei Orgânica da Assistência Social (LOAS) - Lei 8742/93 tenha sido aprovada em 1993, somente tomou corpo em 2005 e vem passando por ajustes a cada gestor federal de plantão (Cordeiro, 2018).

Nesse contexto, a reflexão sobre a inserção profisssional e a formação de psicólogos para a construção de políticas públicas que operacionalizam direitos e fortalecem garantias sociais é fundamental para aqueles que se preocupam com os caminhos da formação em psicologia. A entrada desses profissionais nos equipamentos da assistência social reorganiza processos de trabalho, reconstrói equipes e problematiza a inserção profissional da categoria; se até 1980 seu grande espaço de trabalho era o consultório, a Constituição de 1988 altera esse cenário, incorporando milhares de psicólogos às políticas públicas da assistência social (Cruz \& Guareschi, 2014).

Dessa forma destaca-se que a prática da psicologia, historicamente marcada pelo trabalho na clínica privada e oferecida àqueles que podiam pagar, é notadamente alterada com sua incorporação às políticas públicas. Esse novo espaço de ação profissional impulsiona os centros de formação a refletir sobre a formação ofertada aos psicólogos que, incorporados aos equipamentos que operacionalizam políticas de assistência social, estabelecem outros processos de trabalho e práticas, abrangendo grupos populares, famílias e sujeitos em situação de vulnerabilidade (Rivero \& Torossian, 2014).

Diante desse cenário, este artigo discorre sobre o histórico, os conceitos e a estruturação das políticas públicas, destacando que a entrada da psicologia no campo da assistência social resgata o compromisso social da categoria, afirmando o seu saber e o seu fazer. Apresenta-se parte da pesquisa de mestrado realizada junto a oito psicólogos que atuam em CRAS, enfatizando as categorias de análise que se constituíram a partir de suas "vozes" e percepções sobre a formação acadêmica e o desenvolvimento de práticas nesses equipamentos sociais. 


\section{Psicologia e políticas públicas}

Compreender a interface da Psicologia com as políticas públicas implica considerar que estas são compostas por políticas econômicas e sociais que têm, no Estado, o seu formulador e executor, e que no Brasil, historicamente, estiveram submetidas às necessidades da economia, a serviço dos interesses das elites e fortemente marcadas pela lógica patrimonialista (Vasconcelos, 2006). Destaca-se que o processo de aproximação da psicologia às políticas públicas, no Brasil, está mediado por dois grandes momentos históricos, denominados pré e pós Constituição Federal de 1988, que asseguram e ampliam garantias sociais, fundamentando-se no estado democrático de direito (Cruz \& Guareschi, 2014).

No período anterior à CF de 1988 as práticas desenvolvidas no campo da assistência social tinham como fundamento o assistencialismo, compreendido como uma política de exclusão que retroalimenta a miséria. Na medida em que a lógica anterior ao LOAS não garantia direitos, os pobres assistidos pelo assistencialismo interpretavam a ação do Estado como um favor, uma bondade, e assim mantinham-se na condição de submissão. Essa interpretação foi apontada por Wanderley (2014), que resume: "pobreza e exclusão no Brasil são faces de uma mesma moeda" (p. 25).

A partir da LOAS e do SUAS, as políticas públicas vinculadas ao campo da assistência social assumem outra lógica. O caráter assistencialista é substituído pela garantia de direitos, implementada em equipamentos sociais operados por profissionais do campo psicossocial que incorpora, dentre outros, assistentes sociais e psicólogos que passam a trabalhar com territórios adscritos, com comunidades e famílias em situação de vulnerabilidade.

Assim, ao estabelecer um paralelo entre a estruturação das políticas públicas e a construção das práticas da Psicologia Social Comunitária, faz-se necessário compreender que o trabalho comunitário é mediado por uma ação continuada que implica conhecer o contexto, avaliar seus atores, as condições facilitadoras, os nós críticos e as estratégias possíveis para sua superação.

Outro aspecto a ser destacado diz respeito à estruturação das políticas públicas e ao conceito de comunidade. Sawaia (2014) afirma que o espaço comunitário - ou o termo comunidade - rompe a dicotomia entre coletividade e individualidade, entre o ser humano 
genérico e o individual. Segundo a autora, para além das ações que buscam a tomada de consciência é necessária a tomada de inconsciência; ou seja, compreender os processos que permeiam a construção da subjetividade são um desafio tanto para a Psicologia Social Comunitária como para a Política Pública, pois a comunidade contém individualidade, e não pode ser trabalhada como um consenso, já que o sujeito é singular.

Portanto, é fundamental compreender a ontologia do homem e a singularidade do sujeito, tendo a subjetividade como pressuposto de análise para as discussões que implicam na interface entre a psicologia e as políticas públicas. Entende-se o conceito de subjetividade, segundo González Rey (2003), como

[...] um complexo e plurideterminado sistema, afetado pelo próprio curso da sociedade e das pessoas que a constituem dentro do contínuo movimento das complexas redes de relações que caracterizam o desenvolvimento social. Neste sentido compreender o homem é compreender seus processos de subjetivação, entendendo a subjetividade como "um conceito orientado para gerar visibilidade sobre as formas da realidade que o conceito delimita. (González Rey, 2003, p. 19).

Nesse sentido, as práticas psicológicas inseridas no espaço da política da assistência social são mediadas pelos saberes e fazeres da Psicologia Social Comunitária, que "utiliza-se do enquadre teórico da psicologia social, privilegiando o trabalho com os grupos, colaborando com a formação da consciência crítica e para a construção de uma identidade social e individual orientadas por preceitos eticamente humanos" (Freitas, 2015, p. 73). Neste artigo, esses saberes são compreendidos como um fazer psicologia que refuta o mito da neutralidade científica e de uma prática profissional que pode ser exercida sem que ocorra "envolvimento" entre o técnico e a população atendida. Em outras palavras, não há como não se comprometer, pois a organização de trabalhos comunitários implica no fato de que o psicólogo estabelece um compromisso ético e político para com o grupo social onde desenvolve suas ações.

É preciso considerar que as relações de poder e os aspectos políticos do território onde acontecerão as práticas da Psicologia Social Comunitária influenciarão significativamente o trabalho desse profissional. Dessa forma, ao trabalhar nos equipamentos sociais que têm como objetivo a dignidade humana, o profissional se compromete com a superação do clientelismo, do assistencialismo e da psicologização dos fenômenos psicossociais, fato que permitirá a superação da "coisificação" do sujeito e a construção dos processos de autonomia e emancipação (Montero, 2008; Sawaia, 2014). Superação que só acontece em processos democráticos em que o conhecimento é 
produzido na relação entre os diferentes atores sociais. Onde todos têm direitos a voz e produzem conhecimentos por meio do diálogo estabelecido em relações sociais horizontais e libertárias. Nessa perspectiva, o que é valorizado são as relações, em que ambos os participantes, profissional e população, são sujeitos do conhecimento. Na perspectiva da psicologia social comunitária não existe relação Sujeito-Objeto, mas relação entre Sujeito/Sujeito-Objeto em que ambos procuram no diálogo produzirem conhecimentos e estratégias para o enfrentamento e transformação da realidade (Montero, 2004).

\section{Psicologia e Assistência Social}

A reflexão sobre as aproximações entre as políticas públicas e a Psicologia Social Comunitária ganha contornos ainda mais fortes ao considerar o campo da assistência social como um dos grandes espaços de trabalho que, na atualidade, incorpora o psicólogo entre seus profissionais, tendo no CRAS um dos seus pilares (Macedo \& Dimenstein, 2012). Ressalta-se que a perspectiva de homem e de mundo implícita à Psicologia Social, especificamente em sua aplicação no contexto comunitário, fundamenta-se na compreensão do homem enquanto construção sócio-histórica (Guareschi, 2012).

Como destacado anteriormente, a operacionalização do CRAS tem como precedente a Lei Orgânica da Assistência Social, aprovada em 1993, e o Plano Nacional da Assistência Social, aprovado em 2004. Ambos os documentos estruturam o Sistema Único da Assistência Social (SUAS), aprovado em 2005. Configura-se, assim, um território em disputa, visto que os processos de trabalho e a identidade profissional daqueles que se inserem nesses espaços encontram-se em tensionamento (Cruz \& Guareschi, 2014).

Ainda em relação às políticas de assistência social e sua interface com a Psicologia, destaca-se que o SUAS prevê a organização dos serviços segundo o nível de proteção. Desse modo, a proteção básica é operacionalizada por intermédio dos CRAS, através do acompanhamento das famílias de determinada comunidade e da territorialização das ações e oferta de serviços da Proteção Social Básica. Ou seja, em conformidade com o documento Orientações Técnicas - CRAS, que estabelece as funções da equipe técnica de referência, na qual se insere o psicólogo, o trabalho do 
CRAS está pautado na interdisciplinaridade e visa o enfrentamento das situações de vulnerabilidade e riscos sociais (Brasil, 2009). Compreende-se, assim, que

a interdisciplinaridade é um processo dinâmico, consciente e ativo, de reconhecimento das diferenças e de articulação de objetos e instrumentos de conhecimento distintos, que contribui para a superação do isolamento dos saberes (...). O trabalho em equipe não pode negligenciar a definição de responsabilidades individuais e competências. Deve-se buscar identificar papéis e atribuições, de modo a estabelecer objetivamente quem, dentro da equipe interdisciplinar, encarrega-se de determinadas tarefas. (Brasil, 2009, p. 65).

Vale ressaltar que, embora o processo de trabalho deva ser construído coletivamente e o enfrentamento das vulnerabilidades deva contemplar ações que envolvam todos os componentes, é preciso respeitar as especificidades da formação. Assim, compreender os aspectos relativos às subjetividades dos sujeitos que compõem a comunidade é questão central para os psicólogos das equipes, que devem trazer para o centro dos debates a questão da emoção, pois "ao se introduzir as emoções como questão ético-política, obrigam-se as ciências humanas em geral e à psicologia social em especial, incorporar o corpo do sujeito, até então desencarnado e abstrato, nas análises econômicas e políticas" (Sawaia, 2014, p. 101).

Em relação às emoções, destaca-se as contribuições de Camargo (2004), que aponta a necessidade de compreender as emoções enquanto "construções sociais e históricas significadas pela cultura" (p.176). Segundo a autora, "a organização, o desenvolvimento e a lapidação das emoções no homem dependem da cultura onde ele se insere"; por isso, é fundamental "romper com a visão de que a emoção deve ser controlada, civilizada e domesticada pela razão" (Camargo, 2004, p. 177).

Considerando as contribuições de Sawaia (2014) e Camargo (2004), observa-se que a aproximação da psicologia às políticas públicas e a construção das práticas profissionais nesse campo devem agregar aspectos que envolvem a emoção e a subjetividade, entendendo-os como motores das novas relações que se pretende construir nos espaços da assistência social, vinculadas à construção de uma sociedade, que além de justa, pretende assegurar liberdade de expressão e organização comunitária. Nesse sentido, cabe refletir sobre a formação do psicólogo como apresentaremos a seguir.

\section{Formação do psicólogo}


Sobre a formação de psicólogos, Bastos e Gomide (1989), em conjunto com o Conselho Federal de Psicologia, desenvolveram a pesquisa que originou o livro "Quem é o psicólogo brasileiro?", com amostra (questionários) de 2448 psicólogos de diferentes regiões do país. Duas décadas depois, realizou-se, entre os anos de 2006 e 2008, uma nova pesquisa sobre a profissão de psicólogo no Brasil. Dentre os resultados, o estudo indica o crescimento da abordagem sócio-histórica e o surgimento de outros espaços de trabalho, como a área da saúde e jurídica. A pesquisa também revelou que os psicólogos reconhecem uma distância significativa entre a aprendizagem na graduação e as demandas do exercício profissional, indicando o desafio de "formar profissionais para trabalhar com unidades de análise mais complexas que não o indivíduo, tais como grupos e organizações" e o fortalecimento do "setor público como o maior empregador" (Bastos, 2010, p. 271).

Outro estudo importante da temática foi o realizado por Bock (1997), cuja tese "As aventuras do Barão de Münchhausen na psicologia: um estudo sobre o significado do fenômeno psicológico na categoria dos psicólogos" observa que a compreensão dos psicólogos sobre tal temática está fundada no pressuposto de que o fenômeno psicológico é algo abstrato, naturalizante e essencialista. O estudo de Bock (1997), desenvolvido junto a 44 psicólogos, revela uma concepção de homem que desconsidera a construção histórico-cultural (ou sócio-histórica), implicando em práticas profissionais tecnicistas, fundamentadas no liberalismo clássico - e, por conseguinte, individualistas, já que considera o homem como portador de direitos naturais e propriedades universais. Em contraposição às práticas individualizantes e desvinculadas da realidade social, a autora propõe elementos a serem considerados pelos professores de psicologia e entidades da categoria, para a construção de um projeto de formação de psicólogos na perspectiva crítica.

Rivero (2014) apresenta outras contribuições à discussão sobre formação de psicólogos, pontuando que "a relação entre a condição social neoliberal e capitalista brasileira e a forma como a Psicologia se apresenta para a comunidade"; orienta, assim, para uma formação com “características de tecnificação, disciplinarização, especialismos e descompromisso com a integralidade e demanda comunitária, apoiadas em um modelo de profissional autônomo" (p. 151). O autor destaca que a busca pelo cientificismo e a valorização do modelo individualizante da profissão desconsideram as possibilidades e potenciais existentes na diversidade, de forma que "a psicologia nega a si mesma quando 
volta às costas para aquilo que tem de mais valor: o interesse político e afetivo pelo outro, pelo coletivo, pelo exercício imaterial da vida" (Rivero, 2014, p. 152).

As preocupações de Rivero (2014) e Bock (1997) já haviam sido manifestadas por Coimbra (1995), que denuncia que a formação de psicólogos está marcada pelo "viés positivista, tornando hegemônicos os conceitos de neutralidade, objetividade, cientificidade e tecnicismo, onde nos diferentes discursos, o homem e a sociedade são apresentados como "coisas em si", abstratos, naturais e não produzidos historicamente" (p. 9).

Em um estudo de caso com alunos de psicologia de uma universidade pública, Camargo e Ferrarini (2012) desenvolveram grupos focais voltados à definição, aos objetos e objetivos da Psicologia. As autoras indicam que, segundo os estudantes, a "formação acadêmica não está fornecendo subsídios suficientes para uma articulação entre a teoria e a prática" (p.717). Além disso, os acadêmicos relatam que, muitas vezes, ao responder as demandas do estágio, buscam as respostas no "bom senso", e não na teoria. Revela-se, assim, o risco de se "transformar a teoria em dogma" (p.718) e dessa forma afastar-se do objeto de estudo, aqui traduzido como o homem concreto - a comunidade na qual essas práticas serão desenvolvidas.

As contribuições dos autores apontam a necessidade de repensar a formação do psicólogo brasileiro, pois as práticas profissionais inseridas no campo das políticas públicas e de base comunitária indicam um profissional que precisa responder às condições de adversidade e exclusão. Além disso, deve ser capaz de lidar com as situações complexas, pois à Psicologia faz-se necessário lidar com o que se encontra nas entrelinhas, com as questões que envolvem a subjetividade, estabelecendo novas práticas de subjetivação.

Considerando essa necessidade, foi desenvolvida uma pesquisa com o objetivo de conhecer a práticas dos psicólogos atuantes nos Centros de Referência em Assistência Social (CRAS) na interface com a formação acadêmica.

\section{Método}

A concepção de homem e mundo que orientou a pesquisa referenciada neste artigo sedimentou-se na abordagem sócio-histórica (Aguiar \& Ozella, 2006; Bock, 1997;) ou histórico-cultural (González Rey, 2012), termos que aqui são utilizados como sinônimos. 
Essa concepção se opõe aos pressupostos que afirmam existir uma natureza tipicamente humana, considerando que a "condição humana" só é desenvolvida na realidade social na qual o homem se insere. Essa concepção critica o caráter naturalizante do homem, pois a "naturalização" aponta para uma prática ideológica que camufla sua determinação social, descolando-o da sua realidade, daquilo que lhe constitui e lhe dá sentido (Bock, 1997). Dessa forma, a concepção de homem referenciada nesta pesquisa, além de se opor à naturalização do homem, concebe-o como uma condição, entendendo-o como ativo, social e histórico, construído pelo próprio homem -entendido como grupo social, cujas relações são mediadas pela linguagem.

O ponto de partida para a análise foi o empírico, mas a perspectiva de observação do fenômeno foi qualitativa, pois se desejou ir para além da descrição aparente ou medição superficial do fenômeno; para além do que os dados aparentavam. Ressalta-se que a análise qualitativa busca uma compreensão particular, não se preocupando com generalizações, princípios ou leis, mas buscando no específico, no peculiar e no singular a aproximação com os fenômenos e sua interpretação (González Rey, 2003).

O material empírico foi coletado por meio de entrevistas semiestruturadas com oito psicólogos que atuam nos CRAS. A seleção dos participantes foi realizada em conjunto com a fundação que gerencia esses equipamentos em uma capital da região sul do Brasil. Foram selecionadas as regionais administrativas nas quais atuavam o maior número de psicólogos.

Para análise dos dados coletados utilizou-se a proposta de Gomez, Flores e Jimenez (2002) para pesquisa qualitativa. Esses autores propõem um método de análise composto por três etapas: redução de dados; disposição e transformação dos dados; e obtenção dos resultados e conclusões.

$\mathrm{Na}$ operacionalização da primeira etapa, "redução de dados", fez-se a depravação detalhada das entrevistas e uma categorização prévia, a partir da seleção de trechos dos discursos de cada um dos entrevistados que respondiam ao problema de pesquisa. $\mathrm{Na}$ segunda etapa, "transformação dos dados", os trechos das entrevistas foram organizados em categorias temáticas, de forma a construir uma rede de informações que indicava a interface entre as práticas desenvolvidas pelos psicólogos e a formação acadêmica recebida. Na terceira etapa, "resultados e conclusões", buscou-se estabelecer as relações entre os dados/discursos, articulando-os a pesquisas de outros autores acerca das políticas públicas da assistência social e a formação de psicólogos. 


\section{Resultados}

A condução do percurso metodológico proposto por Gomez, Flores e Jimenez (2002) constituiu quatro categorias de análise:

\section{Categoria 1 - Mal-estar de trabalhar no campo da Assistência Social}

Esta categoria retrata as dificuldades vividas pelos profissionais que atuam nos CRAS e que os leva a considerar a hipótese de se desvincular deste campo, pois se percebem pouco preparados. Em contrapartida, relatam que o trabalho permite-lhes uma realização pessoal de caráter messiânico.

Quando eu entrei na Assistência na Social eu me sentia na China ou em Marte, porque eles falavam umas coisas que, mas aqui eu me sinto útil (...), e isto é o que me faz bem e me leva adiante, pois sinto que estou fazendo alguma coisa, isto é impagável (...).

Discursos como esse também foram observados nas pesquisas de Bock (1997) sobre o trabalho do psicólogo. A autora observou que "a prática aparece também associada à ideia de ajuda ao próximo, de auxílio, de compreensão absoluta, aceitação total" (p. 39). Vale destacar que a incorporação do psicólogo ao campo da Assistência Social ainda causa estranheza aos profissionais que em seu percurso acadêmico não consideraram a possibilidade trabalhar com políticas públicas.

Em contraposição a esse dado, o Censo SUAS (2017) informa que trabalham nos Centros de Referência Especializados de Assistência Social (CREAS) 12.944 psicólogas e psicólogos, fato que reafirma a política pública de assistência social como um dos grandes campos de atuação da categoria e o serviço público como um dos seus maiores empregadores.

Considerando que as discussões que permeiam a temática sobre política ainda são alheias a muitos psicólogos, que a entendem como prática partidária ou que foram formados na crença - ingênua ou ideologizada - da neutralidade científica, observa-se 
que o discurso acima, notadamente permeado pelo mal-estar e pela insegurança profissional ao se inserir em um novo campo de atuação, se justifica.

Como forma de entender esse "mal-estar", vale destacar as pontuações de Macedo e Dimenstein (2012), que se reportam ao trabalho dos psicólogos nas políticas sociais no Brasil. Para os autores, o trabalho comunitário de base territorial, tem aproximado a Psicologia "de uma realidade ainda distante da que comumente conhecemos e discutimos em nossa formação, como também daquela que lidamos nos clássicos lugares de atuação" (p. 187).

Uma pesquisa do Conselho Federal de Psicologia (2001) concluiu que é na área da Psicologia Social que se concentra um dos menores quantitativos de psicólogos. O estudo aponta que somente 1,7 da amostra pesquisada $(n=923)$ informou atuar nesse campo.

\section{Categoria 2: Conflitos de identidade profissional}

Essa categoria contém os discursos dos entrevistados que expressaram o sentido de busca de um lugar na equipe. Revela-se, nesses discursos, uma identidade já construída em campos tradicionais da psicologia, como a escola, clínica e o trabalho. Para essa análise é necessário considerar que a inserção dos psicólogos nos espaços da política pública é fato recente. A identidade profissional é uma construção social, que não está dada pelos protocolos que orientam as práticas profissionais; ocorre, assim, uma entre os "saberes e fazeres" das equipes de CRAS, em especial entre os psicólogos e assistentes sociais:

"eu me lembro das discussões que tinha com os colegas (graduação): então o que diferencia a psicologia social da Assistência Social? Qual vai ser a especificidade do psicólogo na psicologia social em relação ao Assistente Social (...)?".

Um dos aspectos a ser problematizado sobre os conflitos de identidade profissional que permeiam a interface das práticas desenvolvidas pelos psicólogos e pelos assistentes sociais é o trabalho junto aos Conselhos Tutelares (CT), pois com frequência compartilham a ferramenta de intervenção - no caso, a visita domiciliar. Na perspectiva da desnaturalização e da construção de outras práticas de subjetivação, o trabalho junto 
ao CT assume um caráter de ação que afirma e assegura os direitos das crianças e dos adolescentes. Assim, mais que uma visita domiciliar (VD) para responder ao CT, essa prática deve se configurar como uma estratégia de construção da cidadania, como uma forma de se aproximar desse contexto.

Neste sentido, a VD configura-se como caminho para um outro fazer, que permite uma aproximação com o território, com suas "dores" e demandas. Assim, à medida que o psicólogo se apropria desse contexto e dessas pessoas, percebe que, mais do que números ou dados de relatórios, essas famílias são compostas por sujeitos de histórias, protagonistas na construção de outras práticas profissionais para os psicólogos que atuam nos CRAS.

\section{Categoria 3: Bom senso, ecletismo e conhecimentos da clínica tradicional como referenciais teóricos para o trabalho em CRAS}

Nessa categoria, os discursos parecem revelar que onde falta epistemologia sobra bom senso, pois reiteradamente os entrevistados relatam a ausência de referenciais teóricos que sustentem suas práticas, apontando um ecletismo teórico que coloca em xeque a possibilidade - e até mesmo a necessidade - de assumir uma teoria.

Olha, eu sou psicanalista (...), quando comecei, eu tive que montar um grupo de pais e aí eu fui para uma professora minha que é muito comportamental (...), eu não domino a teoria marxista, pelo contrário, e não sei se eu concordo com ela (...).

Também demonstram a preocupação com o risco do "bom senso", seja pela dificuldade em assumir um referencial teórico que entendem ter sido pouco trabalhado na graduação, seja pela pouca importância dada à questão. $\mathrm{O}$ discurso do bom senso aparece em duas formas: enquanto alguns indicam o uso (ou o risco) de se fundamentar no bom senso e percebem a necessidade de buscar referenciais, outros consideram que seu uso é suficiente para lidar com as situações que envolvem o processo de trabalho nos CRAS:

E aí, quando você chega aqui, vê que não dá para aplicar assim... a coisa que você aprendeu na faculdade sobre clínica, porque não se aplica (não cabe ao 
serviço) muita coisa não dá, e de psico social eu tive bem pouco (...) e realmente sinto muita falta disto, de um embasamento teórico (...). Porque a linha de conduta eu acho que não cabe muito (...), aqui você vai mais pelo bom senso, o que você tem, pelo que a pessoa traz.

Os discursos indicam uma série de questionamentos: afinal, como construir uma identidade profissional para atuar em políticas públicas, se os fundamentos são o bom senso e o ecletismo? Essas situações parecem ter desdobramentos ainda mais complexos quando se observa, como constatado por Bastos e Gomide (1989), a existência de uma "junção de orientações teóricas, incompatíveis em seus pressupostos filosóficos e metodológicos, por um mesmo profissional” (p. 11). Dessa forma, embora já tenha se passado quase três décadas, a situação se repete.

Ainda em relação ao bom senso, destaca-se o trabalho de Camargo e Ferrarini (2012), que encontraram o mesmo discurso do "bom senso", nos alunos de graduação, que, "não encontrando modelos de atuação e conceitos teóricos metodológicos para orientar sua atuação profissional, recorrem às suas experiências pessoais" (p.717).

\section{Categoria 4: práticas nos CRAS: fazeres dos psicólogos $x$ conhecimentos}

\section{necessários}

Nessa categoria destaca-se falas que especificam as ações desenvolvidas para responder as demandas assistenciais e administrativas. Consideraram-se também os conhecimentos percebidos como necessários para o desenvolvimento das práticas da psicologia na Assistência Social.

Sobre a formação recebida, alguns discursos citam a necessidade de se preparar para trabalhar com grupos e comunidade, além da necessidade de inserção dos conteúdos referentes às políticas públicas nos programas das disciplinas de Psicologia Comunitária.

Ela não preparou nada para atuar com comunidades; eu sinto muita falta de me preparar para trabalhar com grupos; mas na minha época não preparavam para trabalhar com comunidade, a gente estava preparado para trabalhar com uma pessoa, ou no máximo com um casal que vem com filho, mas não para trabalhar com comunidade, e isto para mim é o mais difícil. 
Sobre as ações que desenvolvem nos CRAS os participantes destacam que, além das atividades assistenciais, também são tomados pela necessidade de responder às demandas do gestor: "então eu fiquei fazendo algumas coisas do programa (referindo-se a um programa institucional), porque agora está acontecendo uma expansão dele, e eu fiquei passando informações como RG e CPF para nossa regional (...)".

Os psicólogos entrevistados destacaram necessidades percebidas no dia a dia de atuação que não foram discutidas ou aprofundadas na formação, como o trabalho com grupos e famílias nos territórios vulneráveis, a necessidade de incorporar saberes interdisciplinares e de oportunizar estágios em comunidades. Apontam, ainda, a importância da disciplina e dos conteúdos específicos de Psicologia Comunitária e da temática das políticas públicas nos currículos e estágios:

Tem que ter um pouco da prática, mas precisa de conhecimento, esta é a parte que fica faltando em (psicologia) social (...), faltou violência doméstica (...). Eu senti falta de direitos, quais são os direitos humanos (...), o que uma criança tem de direito, e esta parte não tinha (...).

Dentre as reflexões promovidas por essa categoria, destaca-se a percepção de que a formação acadêmica precisa ser revista, incluindo as temáticas e recursos teóricometodológicos próprios para o trabalho comunitário. Os discursos indicam também um conflito de práticas, já que, por vezes, o processo de trabalho é permeado por ações de cunho administrativo, que buscam responder às demandas da instituição - e não, necessariamente, aos usuários da política da assistência social.

\section{Considerações finais}

A partir das discussões mencionadas um dos desafios dos psicólogos que atuam em CRAS, é a compreensão do tema das políticas públicas e dos possíveis e necessários caminhos para sua operacionalização. Para tanto é necessário considerar a singularidade 
do território e o funcionamento de cada equipe, o que implicará à psicologia rever práticas e saberes para a construção de outro fazeres que o campo da assistência social a convoca.

Como destacado incialmente, para a construção de outras práticas psicológicas será necessário fazer o estranhamento delas, de forma a rever os paradigmas que se configuram neste campo de atuação, ainda marcado pela lógica essencialista da formação e pelo modelo clínico individualizante, que persistem, talvez de forma ingênua, na contramão do que prevê a política pública da assistência social.

Em contraposição a essa lógica, a política pública busca incluir psicólogos capazes de lidar com os preceitos da integralidade e da intersetorialidade, pautados em práticas que considerem as especificidades do território de atuação que, para além de espaço geográfico, está marcado pelas histórias daqueles que o constituem como espaço de vida, de conflitos, de sentidos e significados.

A pesquisa indicou que, aliada à necessidade de se estranhar as práticas psicológicas que se desenvolvem na PNAS, encontra-se a importância da desnaturalização dos fenômenos sociais, como um olhar crítico frente às verdades estabelecidas, que se solidificam no terreno do senso comum, da supremacia do hegemônico ou do inquestionável. Aliada a essa desnaturalização são necessárias outras práticas de subjetivação, outros modos de pensar e de fazer no campo comunitário; outras práxis, questionando dogmas e práticas que vêm sendo construídos pela psicologia, sua responsabilidade frente ao novo e seus descaminhos por acreditar-se neutra.

Entre as perspectivas da psicologia contemporânea, a histórico-cultural apresenta potencial para orientar a prática do psicólogo na direção da desnaturalização e na crítica à individualização dos problemas humanos, pois compreende a gênese e o desenvolvimento dos processos mentais como construídos nas práticas sociais, culturais e históricas, mediados pelo uso de instrumentos e signos, a partir da participação ativa do homem. Portanto, entende-se que a condição social é geradora do sofrimento, com suas contradições, discordâncias, conflitos e do impedimento do poder de agir que essa condição impõe ao sujeito (Clot, 2010).

Nesse sentido, ao se incorporar às políticas da assistência social, o profissional da psicologia precisa estar atento às inovações e ao compromisso social da categoria, desafiando a sociedade patrimonialista que vê na assistência social uma oportunidade de privatizar práticas - a exemplo do que Vasconcelos (2006) observa ocorrer no Sistema 
Único da Saúde (SUS), no qual forças políticas identificadas com o ideário social conservador se contrapõem aos avanços operacionalizados por essa política de Estado.

Os discursos dos entrevistados apontam a incorporação de conteúdos de políticas públicas aos currículos de psicologia e parecem indicar à academia um rever de sua formação, pois novos fazeres vêm se constituindo no campo da psicologia comunitária. Para tanto, novos saberes se fazem necessários, de forma que os conteúdos referentes às políticas públicas devem configurar diretrizes de formação, e não somente conteúdos programáticos.

A partir dessas ponderações compete à psicologia, e em especial às instituições formadoras, atentar para o tempo histórico e político que se abre para sua incorporação à política pública da assistência social; pois, não os percebendo, abstém-se para que outras categorias o façam.

\section{Referências}

Bastos, A. V. B., \& Gomide, P. I. C. (1989). O psicólogo brasileiro: sua atuação e formação profissional. Psicologia: Ciência e Profissão, 9(1), 6-15.

Bastos, A. V. B., Gondi N, S. M. G., \& Borges-Andrade, J. B. (2010). O psicólogo brasileiro: sua atuação e formação, o que mudou nas últimas décadas? In O. Yamamoto H \& A. L Costa (Orgs.), Escritos sobre a profissão de psicólogo no Brasil (pp. 255271). Natal: EDUFRN.

Bock, A. M. B. (1997). Formação do psicólogo: um debate a partir do significado do fenômeno psicológico. Psicol., Ciênc. Prof. (Impr.), 17(2), 37-42.

Bock, A.M.B. (1997). As Aventuras do Barão de Münchhausen na Psicologia: um estudo sobre o significado do fenômeno psicológico na categoria dos psicólogos - tese de doutoramento em Psicologia Social PUCSP/97

Brasil. Ministério do Desenvolvimento e Combate à Fome (2009). Orientações técnicas. Brasília, DF: Centro de Referência de Assistência Social.

Brasil. Ministério do Desenvolvimento Social (2018). Censo SUAS 2017: análise dos componentes sistêmicos da política nacional de assistência social. Brasília, DF: Ministério do Desenvolvimento Social.

Camargo, D. (2004). As emoções \& a escola. Curitiba: Travessa dos Editores. 
Camargo, D., \& Ferrarini, N. L. (2012). O Sentido da psicologia e a formação do psicólogo: um estudo de caso. Psicol. Soc., 24(3), 710-719.

Coimbra, C. M. B. (1995). Guardiães da ordem: uma viagem pelas práticas PSI no Brasil do milagre. Rio de Janeiro: Oficina do Autor.

Conselho Federal de Psicologia (2006). Quem é o psicólogo brasileiro? São Paulo: EDICON.

Cordeiro, M. P. (2018). A Psicologia no SUAS: uma revisão de literatura. Arquivos Brasileiros de Psicologia, 70(3), 166-183.

Clot, Y. (2010). Trabalho e poder de agir (G. J. Teixeira e M. M. Z Vianna, Trads.). Belo Horizonte: Fabrefactum.

Cruz, L. R., \& Guareschi, N. (2014). Políticas públicas e assistência social: diálogos com práticas psicológicas. 5. ed. Petrópolis: Vozes.

Freitas, M. F. Q. (2015). Psicologia na comunidade, psicologia da comunidade e psicologia (social) comunitária - práticas de psicologia em comunidade nas décadas de 60-90, no Brasil. In R. H. F Campos (Org.), Psicologia comunitária: da solidariedade à autonomia (pp. 54-80). 20 ed. Petrópolis: Vozes.

Gomez, G. R., Flores, J. G., \& Jiménez, E. G. (2002). Metodología de la investigación cualitativa. Santiago de Cuba: Prograf.

González Rey, F. G. (2003). Sujeito e subjetividade: uma aproximação histórico cultural. São Paulo: Pioneira Thonson Learning.

González Rey, F. G. (2012). O social na psicologia e a psicologia social: a emergência do sujeito. 3. ed. Petrópolis: Vozes.

Guareschi, P. (2012). Psicologia social crítica: como prática da libertação. 5. ed. Porto Alegre: EDIPUCRS.

Macedo, J. P., \& Dimenstein, M. (2012). O trabalho dos psicólogos nas políticas sociais no Brasil. Avances en Psicologia Latinoamericana, 30(1), 182-192.

Montero, M. (2004). La participación y el compromisso em el trabajo comunitario. In M. Montero (Org.), Introducción a la psicologia comunitária: desarrollo, conceptos y procesos (pp. 108-122). Buenos Aires: Paidós. 
Rivero, N. E. E. (2014). Entre o zumbi e o fantasma: o paradoxo das formações profissionais. In N. M. F Guareschi (Org.), Psicologia, formação, politicas e produção em saúde (pp. 141-156). Porto Alegre: EDIPUCRS.

Rivero, N. E., \& Torassin, S. D. (2014). Políticas públicas e modos de viver: a produção de sentidos sobre vulnerabilidade. In L. R, Cruz \& N. Guareschi, Políticas públicas e assistência social: diálogos com práticas psicológicas (pp. 56-69). 5. ed. Petrópolis: Vozes.

Sawaia, B. (2014). O sofrimento ético-politico como categoria de análise da dialética exclusão/inclusão. In B. Sawaia (Org), As artimanhas da exclusão: análise psicossocial e ética da desigualdade social (pp. 97-118). 14. ed. Petrópolis: Vozes.

Sawaia, B. (2015). Comunidade: a apropriação científica de um conceito tão antigo quanto a humanidade. In R. H. F. Campos (Org.), Psicologia social comunitária: da solidariedade à autonomia (pp. 35-53). 20. ed. Petrópolis: Vozes.

Vasconcelos, C. M. (2006). Política e gestão no SUS: uma interação conflitiva. In J. L. Castro, Política e gestão em saúde: reflexões e estudos (pp. 49-68). Natal: Observatório RN-NESC/UFRN.

Wanderley, M. B. (2014). Refletindo sobre a noção de exclusão. In B. Sawaia (Org.), As artimanhas da exclusão: análise psicossocial e ética da desigualdade social (pp. 1626). 14. ed. Petrópolis: Vozes.

Submetido em: 20/12/2019

Aprovado em: 22/07/2020 